\title{
Determination of Trenbolone Residual in Bovine Liver by Liquid Chromatography-Mass Spectrometry
}

\author{
Hai Wang · Zijian Wang · Bing Shao • \\ Ziru Liu $\cdot$ SuYing Liu
}

Received: 21 December 2007/Accepted: 9 October 2008/Published online: 25 October 2008

(C) Springer Science+Business Media, LLC 2008

\begin{abstract}
A sensitive method was developed and validated for the quantitation of trenbolone residues in bovine liver. Target analytes were extracted from liver homogenate using solid phase cartridges, separated on a Phenyl column and detected using an electrospray ionization mass spectrometer operating in positive ion mode. The mean recovery of the analytes was between $62 \%$ and $69 \%$. The method provided detection capabilities of $1 \mu \mathrm{g} / \mathrm{kg}$ for trenbolone. The method is suitable for application in veterinary drug residue in surveillance programme.
\end{abstract}

Keywords Trenbolone - LC-ESI-MS · Bovine liver · Residue

H. Wang · Z. Wang

State key laboratory of environmental aquatic chemistry,

Research Center for Eco-Environmental Sciences,

Chinese Academy of Science, Shuangqing Street,

Haidian District, Beijing 100085, China

H. Wang $(\bowtie) \cdot$ S. Liu

Quality control and inspection center for animal products,

Ministry of agriculture, China animal disease control center,

Maizidian Street, Chaoyang District, Beijing 100026,

People's Republic of China

e-mail: cadc2008@126.com

B. Shao

Institute of Nutrition and Food Hygiene,

Beijing Center for Disease Prevention and Control,

Hepingli Zhongjie, Dongcheng District, Beijing 100013, China

Z. Liu

Beijing Research Institute of Chemical Engineering and Metallurgy, 145 Jiukeshu, Tongzhou District,

P.O. Box 234, Beijing 101149, China
Trenbolone is a synthetic anabolic steroid used in animal husbandry practices as potent growth-promoter. Abuse of trenbolone can result in endocrine disruption (Kirkwood et al. 1985). Therefore there is need to detect and quantify its residue in various food matrices.

Analytical method for trenbolone was particularly challenging due to its high sensitivity and selectivity required. Radioimmunoassay (Hoffmann 1983), thin-layer chromatography (Laitem et al. 1978) and liquid chromatography with fluorescence detection (Naoki et al. 2000) had been applied to trenbolone detection. However these methods could not provide satisfactory sensitivity or they could easily provide false positive results. GC-MS is a sensitive technique for ammoassay of hormones, but it is time-consuming because it requires derivatization. Due to its structure (Fig. 1), trenbolone gives difficulties with most common derivatizing agents (Daeseleire et al. 1991). In comparison, LC-MS should be a promising technique for trenbolone residual analysis for its high selectivity, sensitivity and no need for derivatization. Liver is the recommended target matrix for the residue control of trenbolone in cattle. In this study, an LC-ESI-MS method to detect trenbolone in bovine liver was described.

\section{Materials and Methods}

Methanol, acetonitrile, hexane, chloroform, 1-propanol, and ethyl acetate were all pesticide residue grade from Fisher (New Jersey, USA). Formic acid (99\%), acetic acid (99\%) were from Acros Organics (New Jersey, USA). Water was purified using a Mill-Q system (Millipore, USA) trenbolone were purchased from Sigma (St.Louis, MO, USA). Sep-Pak silica and amino-propyl solid phase extraction cartridges (3 cc, $500 \mathrm{mg}$ ) were purchased from 
<smiles>CC(=O)O[C@H]1CC[C@H]2[C@@H]3CCC4=CC(=O)CCC4=C3C=C[C@]12C</smiles>

Fig. 1 Molecular structures of trenbolone

Waters Co. (Milford, MA, USA). Stock solutions were prepared for all standard substances at $1000 \mathrm{mg} / \mathrm{L}$ in methanol.

Ten grams of liver was weighed, and put into a $100 \mathrm{~mL}$ glass conical flask. Ten milliliters $0.2 \mathrm{~mol} / \mathrm{L}$ acetate buffer (pH 5.2) was added and the samples were homogenized with an ultra turrax machine for about $1 \mathrm{~min}$. About $35 \mathrm{~mL}$ methanol was added to homogenize the sample. Each mixture was centrifuged at $2000 \mathrm{~g}$ for $10 \mathrm{~min}$. The supernatant was decanted into a separatory funnel and extracted with $20 \mathrm{~mL} n$-hexane twice to remove the parts of fat. The upper layer was discarded ( $n$-hexane) and $5 \mathrm{~mL} 1$-propanol was added to prevent foaming during evaporation. Methanol was evaporated at $50^{\circ} \mathrm{C}$ with a rotary evaporator. One hundred milliliters of water was added and the aqueous solution was subjected to solid phase extraction (SPE).
An HLB cartridge was conditioned sequentially with $6 \mathrm{~mL}$ methanol containing $50 \mathrm{mmol} / \mathrm{L}$ triethylamine, $6 \mathrm{~mL}$ methanol, and $6 \mathrm{~mL}$ water. The aqueous extract was applied to the cartridge at a flow rate of $3-4 \mathrm{~mL} / \mathrm{min}$. The glass reservoir and cartridge were rinsed with $2 \times 4 \mathrm{~mL}$ water. The cartridge was dried with high purity nitrogen. The crude analyte was eluted with $10 \mathrm{~mL}$ methanol containing $50 \mathrm{mmol} / \mathrm{L}$ triethylamine. The eluate was dried under a gentle nitrogen stream. The residue was dissolved by ultrasonication for $30 \mathrm{~s}$ with $0.5 \mathrm{~mL}$ chloroform, and $5 \mathrm{~mL} n$-hexane was added. The solution then was then passed through a Sep-Pak Silica solid phase extraction cartridge conditioning $6 \mathrm{~mL} n$-hexane. Five milliliters of $n$ hexane was used to wash the interferences. The analyte was eluted sequentially with $6 \mathrm{~mL}$ water-saturated ethyl acetate. The eluate was dried under a gentle nitrogen stream, and the residue was redissolved with $2 \mathrm{~mL}$ methanol-ethyl acetate $(40: 60, \mathrm{v} / \mathrm{v})$. The methanol-ethyl acetate solution was applied to amino-propyl solid phase extraction cartridges conditioned with $4 \mathrm{~mL}$ methanol-ethyl acetate (40:60, v/v) and $4 \mathrm{~mL}$ water-saturated ethyl acetate. The eluate was collected and another $2 \mathrm{~mL}$ methanol-ethyl acetate $(40: 60, \mathrm{v} / \mathrm{v})$ was used to rinse the analytes. The eluate was dried under a gentle nitrogen stream. The residue was reconstituted with $0.5 \mathrm{~mL}$ mobile phase and mixed in a vortex stirrer.

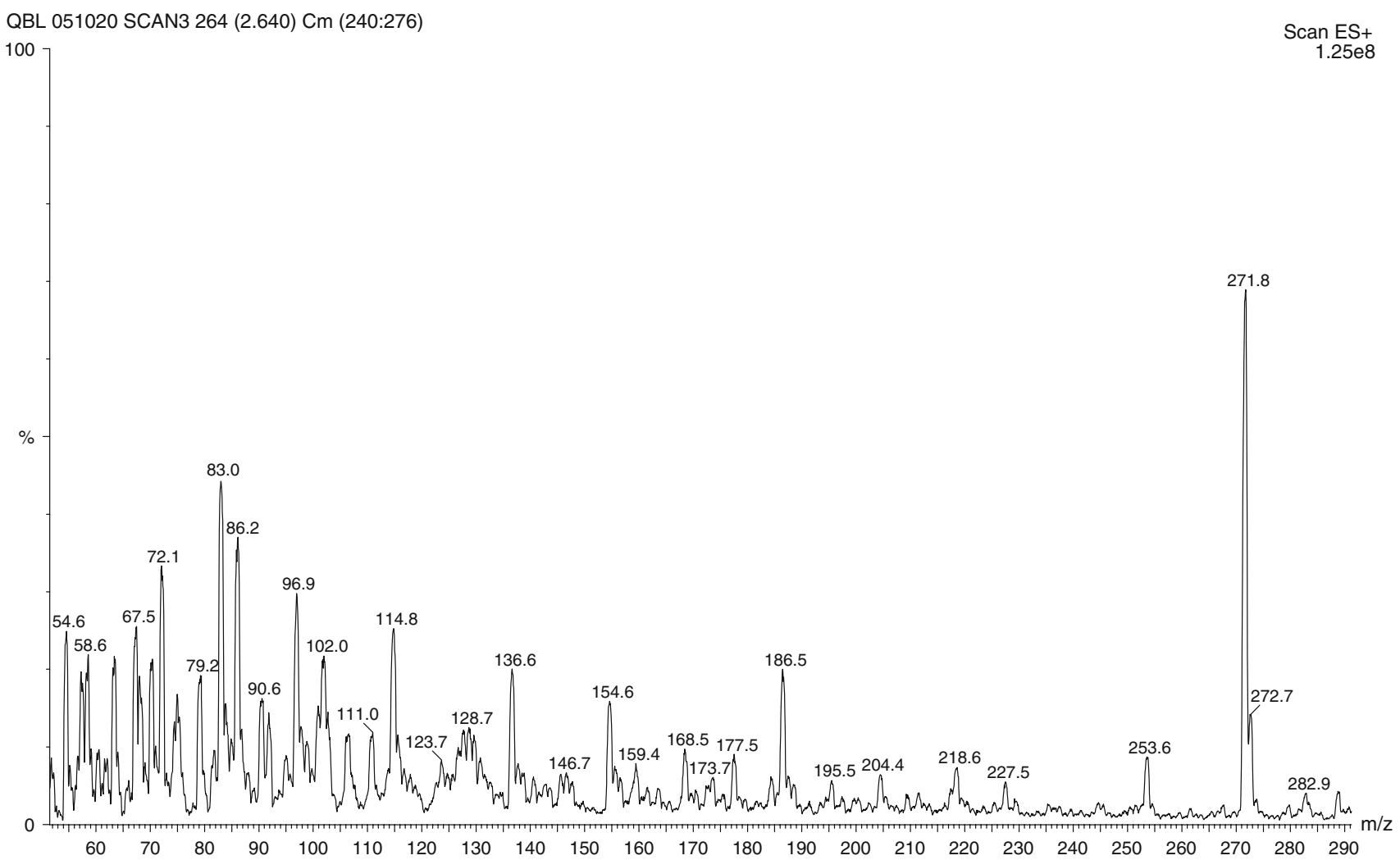

Fig. 2 Full scan spectra of trenbolone 


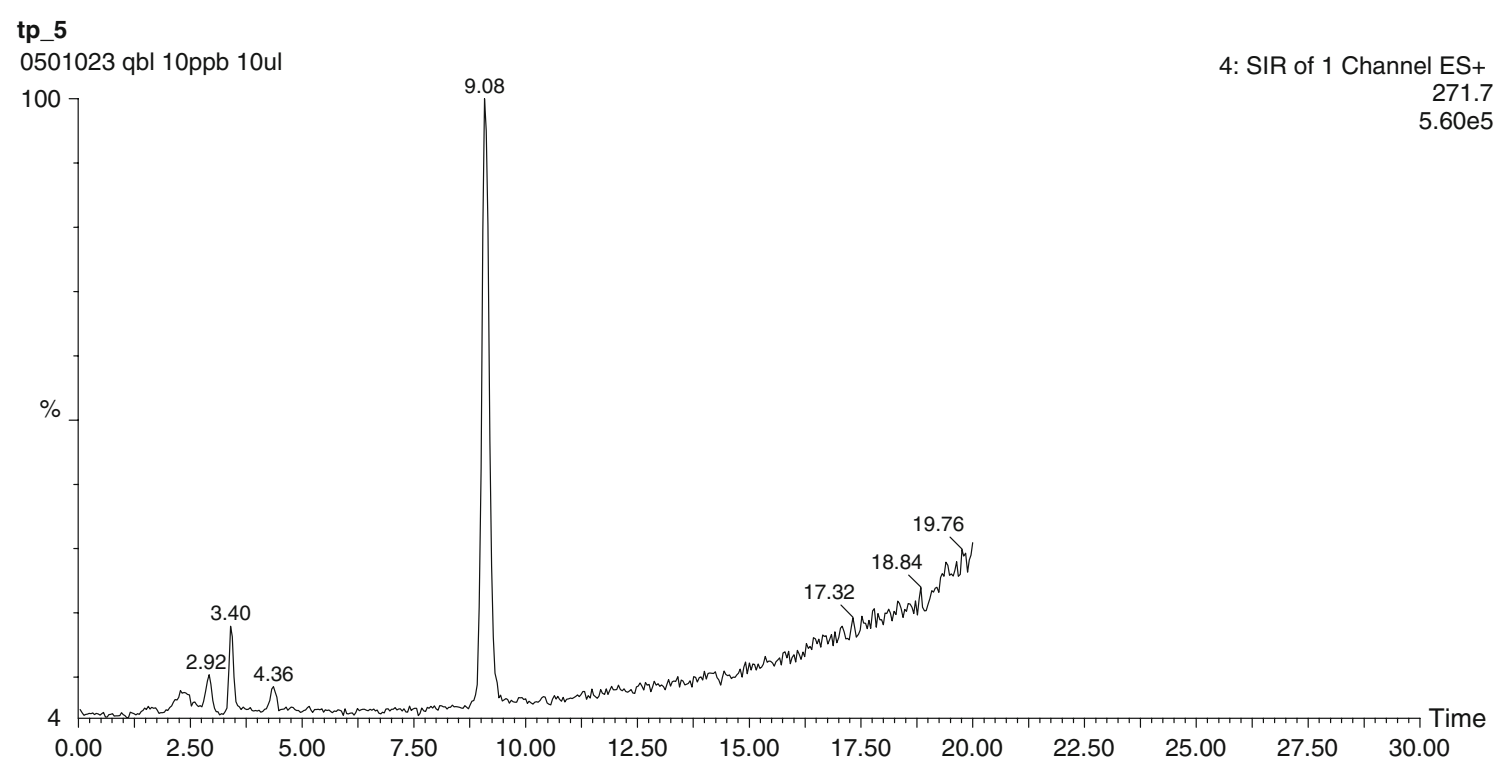

Fig. 3 LC-MS chromatogram of trenbolone standard solution $(10 \mu \mathrm{g} / \mathrm{L})$

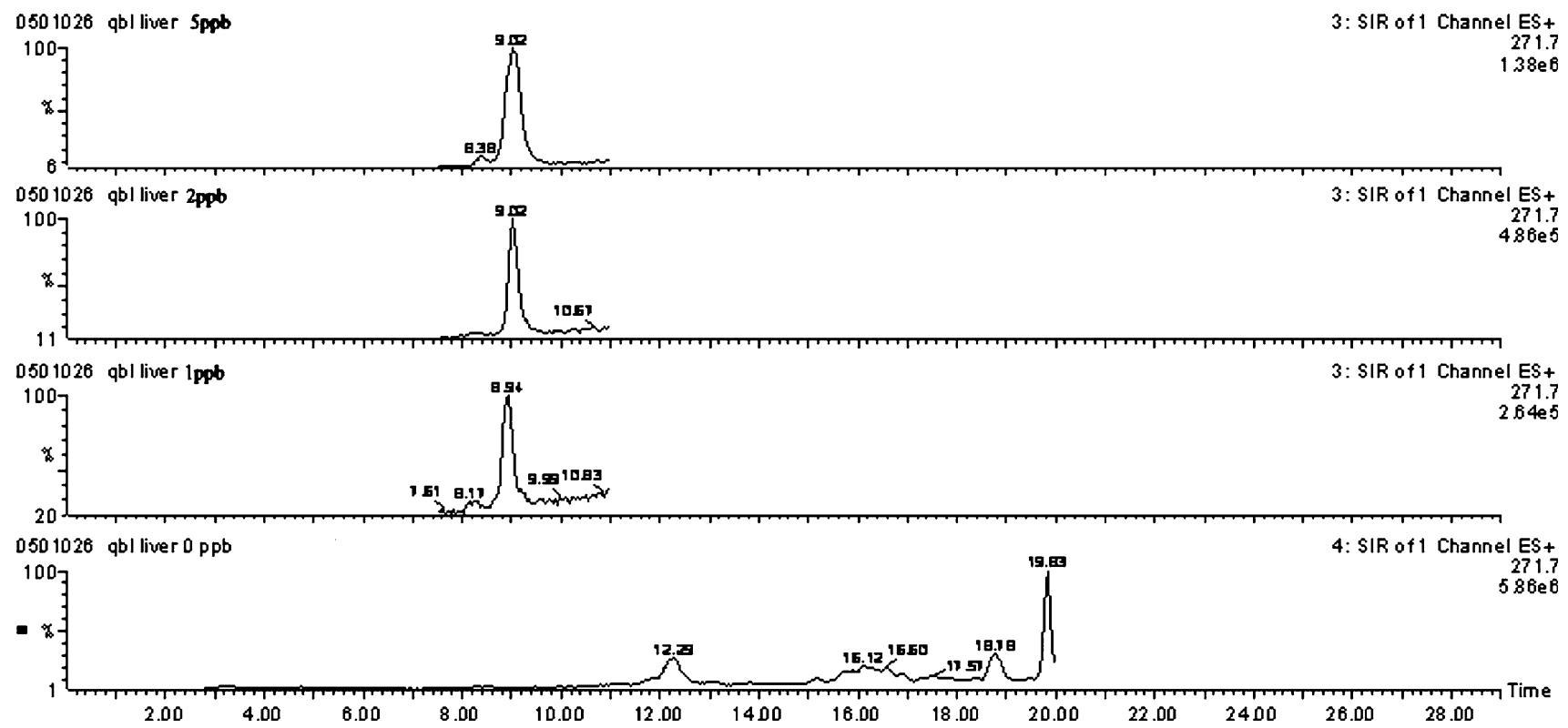

Fig. 4 LC-MS chromatograms of spiking liver sample containing 5, 2, 1, $0 \mu \mathrm{g} / \mathrm{kg}$ of trenbolone

The liquid chromatography mass spectrometer system consisted of a Waters Alliance 2695 LC system equipped with a Micromass (Manchester, UK) ZQ 4000 mass spectrometer. The mass spectrometer was operated in positive mode electrospray ionization. The capillary voltage was held at $2.8 \mathrm{kV}$. The cone voltage was $50 \mathrm{~V}$. The multiplier voltage was $450 \mathrm{~V}$. The nitrogen gas flow of the desolvation gas and cone gas were set to 450 and $0 \mathrm{l} / \mathrm{h}$, respectively. The source temperature and desolvation gas temperature were held at 100 and $300^{\circ} \mathrm{C}$.
Four most abundant product ions were monitored in SIM mode, they were 271.7, 199.0, 165.0 and 157.6, respectively. The CAPCELL PAK Phenyl column $(250 \mathrm{~mm} \times 2.0 \mathrm{~mm}$ i.d. $5 \mu \mathrm{m})$ was used for LC separation. The column temperature was $40^{\circ} \mathrm{C}$, the flow rate was $0.2 \mathrm{~mL} / \mathrm{min}$, and the injection volume was $10 \mu \mathrm{L}$. Methanol and water were used as mobile phases. The initial composition was $35 \%$ of organic phase and $65 \%$ of water. After $3 \mathrm{~min}$, the organic phase was programmed to linearly increase to $100 \%$ in $27 \mathrm{~min}$ and to hold for $5 \mathrm{~min}$ and then 
Table 1 Intra-assay variation for the recovery of the analytes from bovine liver

\begin{tabular}{|c|c|c|c|}
\hline \multirow[t]{2}{*}{ Analyte } & \multirow{2}{*}{$\begin{array}{l}\text { Fortification } \\
\text { level } \mu \mathrm{g} / \mathrm{kg}\end{array}$} & \multicolumn{2}{|c|}{ Recovery (\%) } \\
\hline & & $\begin{array}{l}\text { Mean } \pm \mathrm{s} \\
(n=5)\end{array}$ & RSD \\
\hline \multirow[t]{3}{*}{ Trenbolone } & 1 & $65 \pm 7.9$ & 12.1 \\
\hline & 2 & $67 \pm 7.2$ & 10.7 \\
\hline & 5 & $72 \pm 7.0$ & 9.7 \\
\hline
\end{tabular}

Table 2 Inter-assay variation for the recovery of the analytes from bovine liver

\begin{tabular}{|c|c|c|c|}
\hline \multirow[t]{2}{*}{ Analyte } & \multirow{2}{*}{$\begin{array}{l}\text { Fortification } \\
\text { level } \mu \mathrm{g} / \mathrm{kg}\end{array}$} & \multicolumn{2}{|c|}{ Recovery (\%) } \\
\hline & & $\begin{array}{l}\text { Mean } \pm s \\
(\mathrm{n}=5)\end{array}$ & RSD \\
\hline \multirow[t]{3}{*}{ Trenbolone } & 1 & $62 \pm 8.5$ & 13.7 \\
\hline & 2 & $65 \pm 7.5$ & 11.5 \\
\hline & 5 & $69 \pm 7.3$ & 10.6 \\
\hline
\end{tabular}

decrease to the initial composition in $1 \mathrm{~min}$. The column was then equilibrated for $20 \mathrm{~min}$.

\section{Results and Discussion}

The method was found to be suitable for the determination of trenbolone (Figs. 2, 3, 4).

Linearity of the response was checked from a set of eight working standards ranging in concentration from 2.0 to $250 \mu \mathrm{g} / \mathrm{L}$. Calibration curves were prepared by plotting the peak area versus the analyte concentration. Leastsquares linear regression analysis was used to determine the slope. The curves were found to be linear over this range $\left(r^{2}=0.999\right)$. The limits of detection was determined from representative blank samples. It was equal to three times signal-to-noise. The limit of quantitation for the method was $1 \mu \mathrm{g} / \mathrm{kg}$. The accuracy and precision of the method were determined using liver samples fortified at levels of 1,2 and $5 \mu \mathrm{g} / \mathrm{kg}$. Intra-assay variation was determined by analysing five samples within a single run, mean recovery of the analytes was between $65 \%$ and $72 \%$. RSD were typically at less than $12.1 \%$ (Table 1). Interassay variation was determined by analysing samples on five different occasions to evaluate the run to run variation in the method. Mean recovery of analytes was between $62 \%$ and $69 \%$ with RSD at less than $13.7 \%$ (Table 2).

This method has been used to analyze 10 bovine liver samples available from local market. No trenbolone was detected among the samples.

A sensitive and reliable LC-ESI-MS method for the determination of trenbolone residue in bovine liver was described. This method avoided the most interferences in previous GC-MS caused by the derivatization. The limit of quantitation for the method was $1 \mu \mathrm{g} / \mathrm{kg}$ and suitable for inspection of its residue in animal products.

Acknowledgements Funding support from Natural Science Foundation of China (20621703) and the Foundation of Ministry of Science \& Technology of China (2002BA906A75) are gratefully acknowledged.

\section{References}

Daeseleire E, De Guesquière A, Van Peteghem C (1991) Derivatization and gas chromatographic - mass spectrometric detection of anabolic steroid residues isolated from edible muscle tissues. J Chromatogr Biomed Appl 562:673-679. doi:10.1016/03784347(91)80617-L

Hoffmann B (1983) Use of radioimmunoassay procedures for the determination of sex hormones in animal tissues. J Steroid Biochem 19:947-951. doi:10.1016/0022-4731(83)90038-9

Kirkwood RN, Moller K, Smith WC, Lapwood KR, Garrick DJ (1985) The influence of allyl trenbolone (Regumate) on the timing, duration and endocrinology of parturition in sows. Anim Reprod Sci 9:163-171. doi:10.1016/0378-4320(85)90020-X

Laitem L, Gaspar P, Bello I (1978) Detection of trenbolone residues in meat and organs of slaughtered animals by thin-layer chromatography. J Chromatogr A 147:538-539. doi:10.1016/ S0021-9673(00)85191-2

Naoki Y, Yumi A, Nobuyuki T (2000) Determination of $\alpha$ - and $\beta$ trenbolone in bovine muscle and liver by liquid chromatography with fluorescence detection. J Chromatogr B Biomed Sci Appl 739:363-367. doi:10.1016/S0378-4347(99)00557-5 